\title{
Modern Development Problems of Russian Healthcare (Part 1)
}

\author{
V. N. Ivanov ${ }^{a}$ and A. V. Suvorov ${ }^{a, *}$ \\ ${ }^{a}$ Institute of Economic Forecasting, Russian Academy of Sciences, Moscow, Russia \\ *e-mail:asuvor@ecfor.ru \\ Received May 17, 2021; revised May 26, 2021; accepted June 3, 2021
}

\begin{abstract}
The paper (part 1) analyzes the dynamics of indicators characterizing the state of health of the Russian population. A comparative analysis of the development of healthcare in Russia and other countries is carried out. The conclusion is confirmed that the main problem in the development of Russian healthcare is the insufficient volume of public funding. The drawbacks and limited potential of the adopted funding model are assessed. A possible way to increase public funding is proposed. It is shown that the availability of medical care is reduced as a result of the so-called optimization of healthcare. A possible way to improve the territorial organization of medical services is considered. The effectiveness of the Russian healthcare system in the fight against the coronavirus pandemic is assessed.
\end{abstract}

Keywords: Russian healthcare, the state of health of the population, availability of medical care, public health spending, COVID-19

DOI: $10.1134 / \mathrm{S} 1075700721060058$

The current state of the national healthcare system raises justified concern. The high morbidity and mortality of the population of Russia persist. Sociological studies record a low level of satisfaction of the population with the quality and level of accessibility of medical care. Representatives of the medical community are increasingly criticizing the government's policy in the field of healthcare, the adopted directions of reforming the industry. At the same time, many of the shortcomings of the implemented strategy for organizing healthcare have been clearly manifested during the epidemic of coronavirus infection COVID-19 and caused significant damage to the socio-economic development of the country.

The state of health of the population. According to official data, in 2018 the total number of registered diseases in the country's residents amounted to $240 \mathrm{mln}$, i.e., on average, 1.6 diseases per person. ${ }^{1}$ Every fourth person has a disease of the circulatory system; in a population sample of 100 people, 13 were diagnosed with diseases of the musculoskeletal system, 12 had diseases of the genitourinary system, 11 had digestion diseases, 10 had eye diseases, 8 had diseases of the endocrine system, and 5 had neoplasms.

The fastest growing morbidity in the Russian population was observed in the first half of the 1990s

\footnotetext{
${ }^{1}$ Here and below, if a specific reservation is not made, the indicators are based on the data of the Federal State Statistics Service published in the "Russian Statistical Yearbook," statistical collections "Healthcare in Russia," "Demographic Yearbook of Russia," "Social Position and Living Standard of the Population of Russia," and "Regions of Russia."
}

during the period of change in the social system, which was characterized by a sharp drop in the level and deterioration of living conditions of the population. An increase in morbidity was observed in relation to almost all classes of diseases, including curable diseases, which were considered almost completely eliminated in the Soviet period. So, for example, in comparison with 1991, the number of patients with a diagnosis of active tuberculosis established for the first time in their life increased by the mid-1990s by more than two times, and the number of patients with a diagnosis of syphilis grew 30 times.

In the 2000s, as compared to the previous decade, the rate of growth in the incidence of diseases of the circulatory system (the number of registered diseases in patients diagnosed for the first time in their lives) increased, while it decreased in many other classes of diseases (Table 1). At the same time, the incidence rate in 2019 was lower than in 1991 only for infectious diseases. Meanwhile, over the past almost thirty years, the number of detected diseases of the endocrine system has increased three and a half times, the number of detected diseases of the circulatory system has grown more than three times, and the number of neoplasms has twice increased. The last two classes of diseases as well as external causes (accidents, traffic injuries, homicides and suicides) are currently the main causes of mortality in the population.

The dynamics of the mortality rate of the population include three time intervals: 1991-1995, 19952005, and 2005-2019. In the early 1990s, there was a maximum increase in the overall mortality of the pop- 
Table 1. The incidence rate for main classes of diseases (registered diseases in patients with a diagnosis established for the first time in life), thousands

\begin{tabular}{|c|c|c|c|c|c|c|}
\hline Class of diseases & 1991 & 2000 & 2019 & $\begin{array}{c}2000 \text { in } \% \\
\text { to } 1991\end{array}$ & $\begin{array}{c}2019 \text { in \% } \\
\text { to } 2000\end{array}$ & $\begin{array}{l}2019 \text { in \% } \\
\text { to } 1991\end{array}$ \\
\hline Infectious diseases & 4949 & 6448 & 3902 & 130 & 61 & 79 \\
\hline Neoplasms & 855 & 1226 & 1744 & 144 & 142 & 204 \\
\hline $\begin{array}{l}\text { Diseases of the circulatory } \\
\text { system }\end{array}$ & 1631 & 2483 & 5136 & 152 & 207 & 315 \\
\hline Endocrine system diseases & 586 & 1234 & 2117 & 211 & 171 & 361 \\
\hline Respiratory diseases & 52162 & 46170 & 52278 & 89 & 113 & 100 \\
\hline $\begin{array}{l}\text { Diseases of the digestive } \\
\text { system }\end{array}$ & 4234 & 4698 & 4694 & 111 & 100 & 111 \\
\hline
\end{tabular}

Table 2. Mortality from the main death causes (deaths from all causes per 100000 people)

\begin{tabular}{|c|c|c|c|c|c|}
\hline Death cause & 1991 & 1995 & 2005 & 2019 & $\begin{array}{c}2019 \text { in } \% \\
\text { to } 1991\end{array}$ \\
\hline From all causes in total & 1139 & 1498 & 1605 & 1225 & \\
\hline in $\%$ to the previous date & & 137 & 107 & 76 & 108 \\
\hline in working age & 488 & 798 & 828 & 482 & \\
\hline in $\%$ to the previous date & & 164 & 104 & 58 & 99 \\
\hline From neoplasms in total & 198 & 203 & 201 & 204 & \\
\hline in $\%$ to the previous date & & 103 & 99 & 101 & 103 \\
\hline in working age & 103 & 102 & 88 & 74 & \\
\hline in $\%$ to the previous date & & 99 & 87 & 84 & 72 \\
\hline From diseases of the circulatory system in total & 621 & 790 & 905 & 573 & \\
\hline in $\%$ to the previous date & & 127 & 115 & 63 & 92 \\
\hline in working age & 137 & 224 & 264 & 147 & \\
\hline in $\%$ to the previous date & & 163 & 118 & 56 & 107 \\
\hline From external causes in total & 142 & 237 & 220 & 94 & \\
\hline in $\%$ to the previous date & & 166 & 93 & 43 & 66 \\
\hline in working age & 172 & 311 & 270 & 117 & \\
\hline in $\%$ to the previous date & & 181 & 87 & 43 & 68 \\
\hline From other diseases in total & 178 & 268 & 279 & 355 & \\
\hline in $\%$ to the previous date & & 151 & 104 & 127 & 199 \\
\hline in working age & 76 & 162 & 206 & 145 & \\
\hline in $\%$ to the previous date & & 213 & 128 & 70 & 191 \\
\hline
\end{tabular}

ulation, which was due, first of all, to a significant deterioration in the socio-economic situation in the country: a deep economic recession, a sharp drop in the standard of living for the majority of the population and an accompanying increase in socio-psychological tension as a result of the inability adapt to new economic conditions [1]. Moreover, this inability was most characteristic of the younger age cohorts of the population. This is confirmed by the significantly higher growth in mortality at the working age (Table 2).

The increase in mortality in 1991-1995 was noted for all major classes of death causes, while the increase in mortality from external causes was the greatest, which was a direct consequence of the growth of socio-psychological tension. In this regard, it should be noted that social and psychological stress is recognized by WHO experts as main among socioeconomic factors that negatively affect the health of the population and lead to the development of cardiovascular diseases, an increase in mortality from accidents, homicides and suicides; at the same time, this influence is most pronounced in the countries that are carrying out accelerated economic transformations without an adequate social policy [2]. 
The degradation of the medical care system also contributed to the growth in mortality in the first half of the 1990s. As radical economic transformations began, funding for Russian healthcare collapsed. The reduction in funding and the deterioration of the material and technical support of the healthcare system resulted in the transition to simplified medical technologies, which in many cases did not provide the previously achieved quality of medical care. This could not but lead to a decrease in its effectiveness.

During the next time interval (1995-2005), the growth rate of total mortality decreased significantly. At the same time, mortality from external causes, primarily in the working age, had a clear tendency to decrease, while mortality from cardiovascular diseases (the main cause of mortality in the population) continued to grow and increased by almost one and a half times compared with 1991. It is due to mortality from diseases of the circulatory system that the increase in the total mortality of the population occurred in the period under review.

It became possible to reverse the growth trend in mortality only in the middle of the 2000s as a result of both an improvement in the socio-economic situation and living conditions of the population and improvement in the medical care system. The latter was facilitated primarily by implementing measures for strengthening the material and technical base of healthcare within the framework of the "Health" national project, which was launched in 2006: largescale procurement of modern medical equipment, and introduction of modern medical technologies.

Over the past 15 years (2005-2019), the rate of mortality from diseases of the circulatory system and external causes has decreased most significantly. As the socio-economic situation in the country began to improve, mortality from external causes began to decline rapidly and decreased by a third by 2019 compared to 1991 . The reduction in mortality from diseases of the circulatory system must be attributed-in contrast to the decrease in mortality from external causes - to achievements of healthcare as a result of the modernization of the system of medical care for patients with cardiovascular diseases: the organization of a network of vascular centers and vascular departments of hospitals, a multiple increase in the number of surgeries on the heart and blood vessels. At the same time, it should be noted that mortality from diseases of the circulatory system in Russia continued to remain at a significantly higher level compared to most economically developed countries [3]. There is also reason to believe that the rate of mortality from diseases of the circulatory system officially registered in recent years is artificially underestimated. Experts explain this by the fact that the achievement of the target rates of mortality from cardiovascular diseases defined by the 2012 presidential decrees in May is one of the criteria for assessing the performance of regional leaders.
Table 3. Average life expectancy (years)

\begin{tabular}{l|c|c|c|c}
\hline & 1990 & 1995 & 2005 & 2019 \\
\hline Men and women & 69.2 & 64.5 & 65.4 & 73.3 \\
Men & 63.7 & 58.1 & 58.9 & 68.2 \\
Women & 74.3 & 71.6 & 72.4 & 78.2 \\
Difference in men and & 10.6 & 13.5 & 13.5 & 10.0 \\
women & & & & \\
\hline
\end{tabular}

As a result, the regions often indicate another concomitant disease of the patient as the cause of death at the suggestion of their leaders [4]. This is probably the reason for the hard-to-explain increase in mortality from "other diseases" just in elderly patients who usually have several diseases (see Table 2).

A generalizing characteristic of the mortality rate and one of the main indicators for assessing the health of the population and the effectiveness of the functioning of the healthcare system is the indicator of average life expectancy (life expectancy at birth). The dynamics of the average life expectancy indicator also include three time intervals (Table 3 ).

In the early 1990s, there was a sharp decline in life expectancy, which was unprecedented in peacetime, primarily for men (see Table 2). From the mid-1990s to the mid-2000s, the values of this indicator remained almost unchanged. The observed insignificant increase in the average life expectancy with a simultaneous growth in the total mortality of the population during this period is mainly explained by the decrease in mortality from external causes during this period due to the significantly lower average age of death in comparison with other death causes.

During 2005-2019, the average life expectancy grew, while the difference in the average life expectancy between men and women also decreased due to the higher growth rates for men (see Table 3). A significant increase in average life expectancy during this period was primarily due to a decrease in mortality from cardiovascular diseases and mortality from external causes. At the same time, the decrease in mortality from external causes not only made a significant contribution to the growth of average life expectancy, but also largely determined the decrease in the difference in the average life expectancy between women and men due to the lower average age of death from this cause with a fourfold excess of its level in men compared to women. Along with the reduction in mortality from diseases of the circulatory system, a significant decrease in infant mortality must be attributed to the unconditional achievements of domestic healthcare, which contribute to an increase in average life expectancy. The infant mortality rate (the number of children who died under one year of age per 1000 live births) decreased almost three times: from 11.0 in 2005 to 4.1 in 2019. 
Table 4. Life expectancy (in 2019) in Russia and in a number of developed countries, years

\begin{tabular}{l|c|c|c}
\hline \multicolumn{1}{c|}{ Country } & Men and women & Men & Women \\
\hline Russia & 73.3 & 68.2 & 78.2 \\
Australia & 83.0 & 81.3 & 84.8 \\
Austria & 81.6 & 79.4 & 83.8 \\
Belgium & 81.4 & 79.3 & 83.5 \\
United Kingdom & 81.4 & 79.8 & 83.0 \\
Germany & 81.7 & 78.7 & 84.8 \\
Spain & 83.2 & 80.8 & 85.7 \\
Italy & 83.0 & 80.9 & 84.9 \\
Canada & 82.2 & 80.4 & 84.1 \\
New Zealand & 82.0 & 80.4 & 83.5 \\
Norway & 82.6 & 81.1 & 84.1 \\
Finland & 81.6 & 79.2 & 84.0 \\
France & 82.5 & 79.8 & 85.1 \\
Japan & 84.3 & 81.5 & 86.9 \\
\hline
\end{tabular}

Despite the observed upward trend in the average life expectancy of the population, Russia is still among the second hundred countries of the world in the WHO ranking for this indicator [5]. In most developed countries, the average life expectancy of the population is eight to ten years higher than in Russia, and the difference in the life expectancy between women and men is two times less (Table 4). The reasons for Russia's lag behind other developed countries have a more than half a century history and are explained, first of all, by insufficient financing of the Russian healthcare system.

Health financing. A global trend is a change in the so-called epidemiological revolutions. By the middle of the 20th century, developed countries almost completed the first epidemiological revolution, which was characterized by significant successes in the fight against diseases that are curable in nature. One of the main results was a significant decrease in mortality, primarily in infant mortality and mortality in working age. As a result, average life expectancy increased by 1960 to about 70 years in most developed countries.

The second epidemiological revolution meant a replacement of the strategy of "treatment up to recovery" with the strategy of prevention and "postponement of fatal complications" of chronic diseases (atherosclerosis, diseases associated with metabolism, etc.), i.e., "moving deaths from these causes to older ages, an increase in the average age of death from them, and, ultimately, a significant increase in life expectancy" [6].

The implementation of such a strategy requires the development and introduction of new medical technologies, diagnostic and therapeutic equipment, an increase in the number of people employed in health- care, and the development of pharmaceutical production. All this leads to a significant rise in the cost of medical care and, accordingly, to a significant increase in healthcare costs.

As a result, the dynamics of spending on healthcare have become an indicator of the dynamics of the volume of medical services of the quality required to solve the problems of the second epidemiological revolution. At the same time, it is considered that one of the most adequate indicators of not only the quality, but also the availability of medical care for the population is the value of public expenditures on healthcare and, in particular, the indicator of the share of these expenditures in the gross domestic product (GDP), which allows for cross-country comparisons, including comparison of countries with different levels of economic development. This indicator to the greatest extent reflects the state of health of the population, mortality rate and average life expectancy.

As the analysis shows, there has been a rapid increase in healthcare expenditures since the 1960s in almost all foreign developed countries. At the same time, the growth rates of public healthcare financing significantly exceeded the rates of economic growth of the countries; as a result, the share of these expenditures in GDP increased by no less than 2-3 times by 1990 compared to 1960 . Simultaneously, the average life expectancy increased by 5-7 years in most developed countries (see Table 4).

In our country, the problems of the first epidemiological revolution were solved quite successfully. As a result, life expectancy increased from 43 years in 1926-1927 (data for the European part of the Russian Soviet Federative Socialist Republic) up to 68.8 years in 1960 . The country entered the top twenty countries of the world by this indicator, being only slightly inferior to the leading countries. However, in the next 30 years, the average life expectancy did not increase and in 1990 it was equal to only 69.2 years. At the same time, as calculations show, the amount of public health spending that was calculated as a share of GDP remained almost unchanged. This indicator (Table 5) in 1990 remained at the level of spending in most developed countries in the 1960s.

The development of domestic healthcare in the period under review followed the path of building up the network of medical institutions and increasing the training of medical personnel. As a result, the number of hospital beds and the number of doctors in the Russian Soviet Federative Socialist Republic increased more than twice. Given the size of the country's territory and the nature of the population's settlement, such an extensive direction of healthcare development seems to be a fully justified way of ensuring universal access to medical care. At the same time, insufficient funding did not make it possible to ensure an improvement in the quality of medical care by the technical and technological re-equipment of domestic health- 
Table 5. Public health spending (\% of GDP) and average life expectancy (years) in the Soviet Union and other countries in 1960-1990*

\begin{tabular}{l|c|c|c|c|c|c|c|c}
\hline \multirow{2}{*}{ Country } & \multicolumn{4}{|c|}{ Public health spending } & \multicolumn{4}{c}{ Average life expectancy } \\
\cline { 2 - 8 } & 1960 & 1970 & 1980 & 1990 & 1960 & 1970 & 1980 & 1990 \\
\hline Soviet Union & 2.8 & 2.9 & 3.0 & 2.9 & 68.8 & 68.8 & 67.5 & 69.2 \\
Australia & 2.3 & 3.4 & 4.3 & 5.1 & 70.9 & 70.8 & 74.6 & 77.0 \\
Austria & 3.0 & 3.3 & 5.1 & 5.1 & 68.7 & 70.0 & 72.6 & 75.5 \\
Belgium & 2.1 & 3.6 & 5.5 & 6.8 & 70.6 & 71.0 & 73.4 & 76.1 \\
United Kingdom & 3.3 & 3.5 & 5.0 & 5.0 & 71.1 & 72.0 & 73.2 & 75.7 \\
Germany & 2.7 & 3.9 & 5.6 & 6.4 & 69.6 & 70.6 & 72.8 & 75.3 \\
Spain & 0.9 & 2.3 & 4.2 & 5.1 & 69.1 & 72.0 & 75.6 & 76.8 \\
Italy & 3.0 & 4.4 & 5.6 & 6.1 & 69.1 & 72.0 & 74.0 & 76.9 \\
Canada & 2.3 & 4.9 & 5.3 & 6.6 & 71.1 & 72.7 & 75.3 & 77.6 \\
New Zealand & 3.5 & 4.1 & 5.1 & 5.7 & 71.2 & 71.5 & 73.2 & 75.4 \\
Norway & 2.6 & 4.0 & 5.9 & 6.3 & 73.6 & 74.2 & 75.8 & 76.6 \\
Finland & 2.1 & 4.1 & 5.0 & 6.2 & 69.0 & 70.2 & 73.4 & 74.8 \\
France & 2.4 & 3.8 & 5.6 & 6.4 & 69.9 & 71.7 & 74.1 & 76.6 \\
Japan & 1.8 & 3.1 & 4.7 & 4.6 & 67.8 & 72.0 & 76.1 & 78.9 \\
\hline
\end{tabular}

* The data for the Russian Soviet Federative Socialist Republic barely differed from the data for the Soviet Union. Data for foreign countries were calculated according to $[7,8]$.

Table 6. Public health spending (at constant 1995 prices) and average life expectancy

\begin{tabular}{c|c|c|c|c|c}
\hline Indicator & 1995 & 2000 & 2005 & 2010 & 2018 \\
\hline Public spending, mln rubles* & 56160 & 37425 & 78071 & 110889 & 152315 \\
\% to 1995 & 100 & 67 & 139 & 197 & 271 \\
Average life expectancy, years & 64.5 & 65.3 & 65.4 & 68.9 & 72.9 \\
\hline
\end{tabular}

* In 1995-bln Rubles.

care, which was necessary to solve the problems of the second epidemiological revolution. Calculations show, in particular, that the cost of purchasing equipment in total healthcare spending in the period under review was only about $2 \%$ [9].

As a result of insufficient funding, the provision of medical organizations with modern diagnostic and treatment equipment, the use of advanced medical technologies remained at an extremely low level. The provision of modern medicines was also very low. In addition, insufficient funding led to low wages in healthcare. Despite the high educational and professional levels of people employed in this sector, the average salary in healthcare was a quarter lower than the average for the national economy. Our country also lagged significantly behind other developed countries in terms of the ratio of the average wages in healthcare to the this indicator in the economy as a whole.

In the early 1990 s, there was a collapse in funding for Russian healthcare. The scale of the fall in public spending is evidenced, first of all, by a sharp decline in wages for people employed in healthcare, which is the main item of expenditure of medical organizations. Calculations show that this indicator decreased in constant prices three times in the first year of radical reforms, and in 1995 it amounted to $47 \%$ of the 1991 level. Due to the unreliability of statistics on the values of the deflator of GDP elements in 1992, it is difficult to give an accurate estimate of the magnitude of the fall in total public health spending from 1991 to 1995. According to our calculations with corrections of data for 1992, public health financing decreased about twice over this period.

Table 6 shows the dynamics of the indicator of public health spending for the period from 1995 to 2018 in constant prices, which was calculated on the basis of the deflator of final consumption as an element of the use of GDP.

As can be seen from the cited data, public health spending continued to decline in the second half of the 1990 s, and the 2000s brought about an increase in financing for healthcare along with the growth of the economy. Given the two-fold drop in funding in the 
Table 7. Public health spending and average life expectancy in the Russian Federation and other countries in 2018*

\begin{tabular}{l|c|c|c}
\hline \multicolumn{1}{c|}{ Indicator } & Spending, \% of GDP & Per capita spending in USD at PPP** & Average lifespan, years \\
\hline Russian Federation & 3.2 & 1030 & 72.9 \\
Australia & 6.4 & 3453 & 82.6 \\
Austria & 7.6 & 3992 & 81.7 \\
Belgium & 8.0 & 3807 & 81.6 \\
United Kingdom & 7.7 & 3215 & 81.3 \\
Germany & 8.7 & 4669 & 81.1 \\
Spain & 6.3 & 2359 & 83.4 \\
Italy & 6.5 & 2537 & 83.0 \\
Canada & 7.8 & 3631 & 82.0 \\
New Zealand & 7.3 & 3099 & 81.9 \\
Norway & 8.7 & 5258 & 82.7 \\
Finland & 7.0 & 3249 & 81.7 \\
France & 8.6 & 3823 & 82.6 \\
Japan & 9.2 & 4003 & 84.2 \\
Average for OECD countries & 6.2 & 2835 & 80.7 \\
\hline
\end{tabular}

* Data for the OECD countries are given according to [10]. ** Per capita spending is calculated using PPP of final consumption in GDP.

first half of the 1990s, this growth is a recovery growth. The level of funding in 1991 was achieved only in 2010. It is interesting to note that the indicator of average life expectancy in 2010 (68.9 years) became exactly the same as in 1991.

In the second half of the 2000s at a relatively high growth rate of public expenditures (average annual growth was $2.8 \%$ ), the state of the material and technical base of healthcare improved. The coefficient of renewal of fixed assets increased several times-up to $6 \%$ in 2010. At the same time, the share of machinery and equipment in the structure of fixed assets grew (up to $39 \%$ in 2010). As noted above, large-scale purchases of modern diagnostic and treatment equipment were carried out during these years within the implementation of the "Health" national project, which made it possible to switch to the use of advanced medical technologies, at least at some medical organizations. First of all, this applies to federal specialized medical centers, the network of which significantly increased, including through the creation of such centers outside Moscow and St. Petersburg.

In general, all this led to an improvement in the quality of medical care and, accordingly, to an increase in its effectiveness. For the first time in Russian history, average life expectancy exceeded the 70 -year threshold in the 2010s and continued to grow until recently. At the same time, the success of the Russian healthcare system significantly lags behind the majority of developed foreign countries. Russia's lag behind these countries in terms of life expectancy not only has not decreased, but has increased over the past three decades. A similar trend is also observed for the difference in public health expenditures calculated as a share of these expenditures in GDP. As for per capita public spending in comparable prices at purchasing power parity (PPP), the scale of Russia's lag behind most developed countries is especially large. In terms of per capita financing, Russia lags almost three times behind the average financing for the countries of the Organization for Economic Cooperation and Development (OECD) and 3.5-5 times behind the countries such as Austria, Germany, Canada, Norway, France, and Japan (Table 7).

Against the background of low public funding in post-Soviet Russia, private spending on healthcare began to grow rapidly: household spending on the purchase of medicines and medical supplies, payments for medical services, and contributions to voluntary medical insurance increased. For the period 1995-2018 in comparable prices, spending for the purchase of medicines and medical goods increased almost 12 times, and spending for payments for medical services grew almost seven times. An advancing growth in private spending was accompanied by an increase in its share in total expenditures on healthcare.

As can be seen from Table 8, the commercialization of Russian healthcare has become an obvious trend.

At the same time, the vector of development was directly opposite to that observed in most developed foreign countries. Historically, the improvement of healthcare systems in these countries followed the path of strengthening the role of the state, the transition from private to public funding. As a result, the current share of private financing in total health spending in developed foreign countries $(23 \%$ in Belgium and France, 22\% in Germany, 21\% in Great 
Britain, $16 \%$ in Japan, $15 \%$ in Norway [10]) is significantly lower than in Russia (39\%).

As many years of world experience have shown, public funding not only ensures universal access to healthcare, but also allows more efficient use of health resources. In Russia, this experience was ignored, including the conclusions of experts that "private financing of healthcare threatens its values and is ineffective in comparison with public financing" [11]. In this regard, it should be noted that healthcare is the most costly in the United States, where private funding dominated until recently. Thus, total expenditures on healthcare in the United States in 2018 amounted to $16.9 \%$ of GDP, which is almost twice more than the average for OECD countries [10]. At the same time, the United States occupies one of the last places in terms of average life expectancy ( 78.6 years) among the countries with a high level of economic development.

The commercialization of Russian healthcare has resulted in the increased inequality in the availability of medical care for the population due to the lack of funds for paid medicine among the majority of the population, especially among its poorest strata. So, for example, according to the data from a sample survey of households cited by Federal State Statistics Service, in $201820 \%$ of the wealthiest citizens accounted for $70 \%$ of paid medical services and $20 \%$ of the poorest people accounted for less than $1.5 \%$, or a share almost 50 times less. According to sample studies, every seventh resident of the country and every fifth pensioner could not purchase the medicines necessary for treatment due to a lack of funds.

At the beginning of the period under review, a reform of public health financing took place: in addition to state budget financing, a compulsory health insurance system (CHI) was introduced in 1993, which provides for employers paying insurance premiums for employees to the state federal and territorial $\mathrm{CHI}$ funds. It should be emphasized that financing through the $\mathrm{CHI}$, i.e., financing by the introduction of compulsory payments for the working population was originally regarded precisely as an addition to financing from the state budget in the context of a sharp decline in the incomes of the latter. This made it possible to dampen the drop in budget financing to a certain extent.

However, later the CHI system began to be considered as the main model for financing healthcare. A transition was made to a one-channel system of financing, in which the budgets of the constituent entities of the Russian Federation transfer certain amounts (contributions) for the nonworking population to the territorial CHI funds. Territorial funds that also receive employers' insurance contributions from the federal CHI fund transfer the accumulated funds to private insurance companies that finance the activities of medical organizations. Meanwhile, some types of medical care as well as capital expenditures, includ-
Table 8. Structure of healthcare expenditures and their share in GDP in 1995 and 2018

\begin{tabular}{l|r|r}
\hline \multicolumn{1}{c|}{ Expenditures } & 1995 & 2018 \\
\hline All expenditures & $100 \%$ & $100 \%$ \\
Public & $84 \%$ & $61 \%$ \\
Private & $16 \%$ & $39 \%$ \\
$\quad$ including for the purchase of & $10 \%$ & $25 \%$ \\
$\quad \begin{array}{l}\text { medicines and goods } \\
\quad \text { for payment of medical services }\end{array}$ & $4 \%$ & $12 \%$ \\
$\quad$ for voluntary medical insurance & $2 \%$ & $2 \%$ \\
$\begin{array}{l}\text { Share of all expenditures as a per- } \\
\text { centage of GDP }\end{array}$ & 4.7 & 5.2 \\
$\begin{array}{l}\text { Share of public expenditures as a } \\
\text { percentage of GDP }\end{array}$ & 3.9 & 3.2 \\
$\begin{array}{l}\text { Share of private expenditures as a } \\
\text { percentage of GDP }\end{array}$ & 0.8 & 2.0 \\
\hline
\end{tabular}

ing the purchase of expensive equipment, are financed exclusively from the state budget.

The above-described complex and contradictory scheme of healthcare financing (public expenditures are carried out by private insurance companies) is only one of the characteristics of the adopted CHI model. Leaving aside for now the assessment of all the negative consequences of the application of this model, we note two important circumstances. First, as international comparative studies show, the CHI model is more costly compared to the system of financing from the state budget and, moreover, does not provide greater efficiency of medical care, in particular, reduction in the mortality rate of the population (for example, see [12]).

Second, despite the declared transition to universal compulsory health insurance, the main source of public funding for healthcare is still the state budget rather than personalized insurance premiums for each insured person, as in other countries applying the CHI model. As calculations show, employers' insurance premiums for employees at a statutory rate amounted in 2018 to just over a third $(36 \%)$ of public health spending despite the increase in this rate from $3.6 \%$ during the introduction of $\mathrm{CHI}$ to $5.1 \%$ in recent years, and budgetary appropriations accounted for the remaining almost two-thirds (calculations were made according to [13]).

Proceeding from these two facts, a natural question arises about the expediency of maintaining funding according to the adopted CHI model. Recently, proposals to return to the state budget financing system have been increasingly formulated by many experts (see, for example, [14-16]), including due to the ineffectiveness of the CHI model under the conditions of the coronavirus pandemic. In 2020, the state allocated additional budgetary funding for the development of a 
Table 9. The maximum personal income tax rate and the amount of the annual income above which the maximum rate is applied

\begin{tabular}{l|c|c|c}
\hline \multirow{2}{*}{ Country } & \multirow{2}{*}{ Rate, $\%$} & Threshold annual income \\
\cline { 3 - 4 } & & units of national currency, thous. & $\begin{array}{c}\text { conversion into Russian rubles } \\
\text { at PPP of currencies*, mln. rubles }\end{array}$ \\
\hline United Kingdom & 47 & 150000 & 5290 \\
Germany & 47 & 277063 & 8992 \\
Italy & 47 & 83263 & 2915 \\
United States & 37 & 523600 & 12592 \\
France & 55 & 587145 & 18434 \\
Japan & 45 & 4000000 & 9127 \\
\hline
\end{tabular}

* Based on the results of international comparisons for 2017.

network of covid hospitals and additional payments to doctors working with coronavirus patients. At the same time, due to a sharp decrease in the number of patients in polyclinics and noncovid hospitals under the conditions of the pandemic, their financing through compulsory medical insurance decreased, which resulted in large accounts payable of medical organizations to insurance companies that pay for their services under compulsory medical insurance [17].

Summarizing the above, one cannot but agree with the experts' conclusion that the fundamental limitation of the financial capabilities of the CHI system is becoming more and more obvious [16]. Moreover, to restore economic growth, it is necessary to increase consumer demand at the expense of the growth in household incomes. Therefore, it seems reasonable to reduce the insurance burden on the wages of employees. In such a situation, in our opinion, the abandonment of the CHI model and the transition to a system of budgetary financing must be considered fully justified.

Under these conditions, an urgent task is to increase significantly state budget spending on healthcare, which is necessary not only to compensate for falling insurance payments, but also to achieve an acceptable level of financing for healthcare in general. The way to solve this problem is also obvious-the state budget revenues must be increased. Until recently, the revenues of the RF consolidated budget amounted to only $35 \%$ of the GDP. This is significantly less than in most developed countries: this figure is $45 \%$ on average for the EU countries, and in Belgium, Denmark and Finland it exceeds 50\% [18].

It is currently recognized that one of the main problems of economic development is an increase in the income gap with an increasing concentration of income among one percent of the population. The importance of solving this problem was acknowledged by the President of the Russian Federation in his speech at the last Davos Forum [19].

In developed foreign countries, a decrease in income concentration is stimulated by high tax rates on incomes of the richest citizens from work and property. As a result, one percent of taxpayers account for most of the collected income tax (in the United States, for example, more than $40 \%$ [20]), which is one of the main items of state budget revenues.

In our opinion, the introduction of a high income tax rate in Russia similarly to developed countries in relation to the incomes of the richest citizens must be considered the first step in solving the problem of increasing the incomes of the consolidated budget of the Russian Federation and, accordingly, increasing public spending on healthcare. The relevance of such a solution is defined as extremely high. According to available estimates, the concentration of income in Russia for one percent of the Russian population corresponds to that in the United States. In both countries, especially in Russia, the authorities are realizing the urgent need to reduce this concentration.

It should be emphasized that we are not talking about the introduction of progressive taxation with a multilevel scale of tax rates in Russia. Objections to the introduction of such a system are to a certain extent justified, given the low income of the vast majority of citizens and the complexity of the administration of such taxation. It is proposed not to go beyond the establishment of an increased tax rate on that part of the income of the richest taxpayers, which exceeds a certain threshold value with maintaining the existing tax rate on all incomes below the established threshold, i.e., incomes of the absolute majority of the population. The amount of the threshold income, above which an increased rate must be applied, as well as the amount of this rate can be determined taking into account the experience of taxation in developed foreign countries: the maximum tax rate they use for that part of an individual's income that exceeds the established threshold. The corresponding calculations for a number of countries [21-23] are given in Table 9. 


\section{REFERENCES}

1. Report on the State Policy in the Field of Health Protection of Citizens and the State of Health of the Population of the Russian Federation in 1993 (Minzdrav of the Russian Federation, Moscow, 1994) [in Russian].

2. The European Health Report 2002 (Regional Office for Europe, World Health Organization, Copenhagen, 2002).

3. N. F. Izmerov, G. I. Tikhonova and T.Yu. Gorchakova, "Mortality of the population of working age in Russia and the developed countries of Europe: trends in the last twenty years," Vestn. Ross. Akad. Med. Nauk, Nos. 7-8, (2014).

4. T. Beskaravaynaya, "Experts of the RANEPA revealed "oddities" in the analysis of the causes of mortality," Medvestnik, 2018, Mar. 12. https://medvestnik.ru/content/news/Eksperty-RANHiGS-vyyavilistrannosti-pri-analize-prichin-smertnosti html. Cited March 21, 2021.

5. Life expectancy and healthy life expectancy, World Health Organization, 2020. https://www.who.int/data/gho/data/themes/mortality-and-global-health-estimates/ghe-life-expectancy-and-healthy-life-expectancy\#: :text-Globally\%2C\%20life\%20xpectancy\%20 has $\% 20$ increased, reduced $\% 20$ years $\% 20$ lived $\% 20$ wi th\%20disability. Cited March 22, 2021.

6. A. G. Vishnevsky, "Mortality in Russia: the failed second epidemiological revolution," Demogr. Obozr. 1 (4), 6-40 (2014).

7. H. Oxley and M. MacFarlan, Health Care Reform. Controlling Spending and Increasing Efficiency (Organization for Economic Cooperation and Development, Paris, 1994).

8. Health at a Glance 2007: OECD Indicators (Organization for Economic Cooperation and Development, Paris, 1994).

9. O. N. Boldov, V. N. Ivanov, B. A. Rosenfeld, and A. V. Suvorov, "Resource potential of the social sphere in the 90s," Probl. Prognozirovaniya, No. 1, 47-64 (2002).

10. Health at a Glance 2019: OECD Indicators (Organization for Economic Cooperation and Development, Paris, 2019).

11. S. Thomson, T. Foubister, and E. Mossialos, Financing Health Care in the European Union (WHO Regional Office for Europe, Copenhagen, 2009).
12. A. Wagstaff, Social Health Insurance vs. Tax-Financed Health Systems-Evidence From The OECD. Policy Research Working Paper No. WPS 4821 (World Bank, Washington, DC, 2009).

13. Report on the results of activities of the Federal Compulsory Medical Insurance Fund in 2018. http://ffoms.ru/upload/medialibrary/6a0/6a027028c1820b87bc18a3f8d280b029.pdf. Cited March, 15, 2021.

14. Yu. M. Komarov, "On a rational system of health protection and medical care," Vestn. Vyssh. Shk. Org. Upr. Zdravookhr., No. 1, 39-46 (2018).

15. G. E. Ulumbekova, Healthcare of Russia. What to Do. Status and Propositions: 2019-2024 (GEOTAR-Media, Moscow, 2019).

16. Yu. Voronin and E. Gontmakher, How to reorganize healthcare in Russia. It is necessary to abandon the insurance financing scheme, Vedomosti, 2020, May 25.

17. Salary background. The Accounts Chamber assessed the budgets of hospitals and clinics, Higher School of Health Organization and Management, 2021, Mar. 4. https://www.vshouz.ru/news/analitika/26386/. Cited March 19, 2021.

18. List of government spending as $\%$ of GDP. https://www.economicshelp.org/blog/158853/economics/list-of-government-spending-as-a-of-gdp/. Cited March 19, 2021.

19. Vladimir Putin spoke at a session of the Davos Agenda 2021 online forum organized by the World Economic Forum, January 27, 2021, Moscow, Kremlin. http://www.kremlin.ru/events/president/transcripts. Cited March 21, 2021.

20. E. York, Summary of the Latest Federal Income Tax Data, 2021 Update. https://taxfoundation.org/federalincome-tax-data-2021/. Cited March 21, 2021.

21. E. Asen, Top Individual Income Tax Rates in Europe, Tax Foundation, 2020, May 7, 2020. https://taxfoundation.org/top-individual-income-tax-rates-ineurope $\bigvee$. Cited March 11, 2021.

22. 2020-2021 federal income tax brackets and rates. https://www.bankrate.com/finance/taxes/tax-brackets.aspx. Cited March 11, 2021.

23. Individual income tax rates in Japan. https://www.jetro.go.jp/en/invest/setting_up/section3/page $7 . h t m l$. Cited March 11, 2021.

Translated by L. Solovyova 